\title{
Surgery and the respiratory muscles
}

\author{
N M Siafakas, I Mitrouska, D Bouros, D Georgopoulos
}

Respiratory muscles are the only skeletal muscles vital to life. Surgical procedures can affect the respiratory muscles by a number of pathophysiological mechanisms including thoracoabdominal mechanics, reflexes, neuromechanical coupling, and loss of muscular integrity. Impairment of respiratory muscle function after surgery may lead to postoperative complications such as hypoventilation, hypoxia, atelectasis, and infections, some of which may be life threatening. In this paper we review surgery that impairs the function of the respiratory muscles - namely cardiac, thoracic, and upper abdominal surgery. Therapeutic interventions or protective measures for respiratory muscles during or after each type of surgery are also briefly addressed. Lung transplantation and lung volume reduction surgery are discussed, since both have been shown to improve the function of respiratory muscles, and possible pathophysiological mechanisms are reviewed. The preoperative assessment of respiratory muscle function is also considered. Furthermore, when postoperative pulmonary complications occur it is worth considering whether the cause could be dysfunction of the respiratory muscles and thus a proper assessment of their function is needed.

\section{Function of the respiratory muscles}

The most important function of the respiratory muscles is breathing since they are the motor arm of the respiratory system. Breathing, a lifelong task, is borne mainly by the inspiratory muscles, especially the diaphragm. The other inspiratory muscles contribute little to quiet breathing but are recruited when higher levels of ventilation are required, such as in exercise and obstructive or restrictive lung disease. The expiratory muscles are not usually used during breathing except at high levels of ventilatory effort. A second function of the respiratory muscles is to perform explosive manoeuvres such as coughing and vomiting. The respiratory muscles also have a role as stabilisers of the thorax and abdomen since they take part in the formation of the thoracic and abdominal walls. Respiratory muscle function depends on the function of the respiratory centres, the spinal motor neurons, the peripheral nerves, and their neuromuscular junctions. ${ }^{1-4}$

Surgery may affect respiratory muscle function by a number of different mechanisms. For example, a surgical incision of the chest or abdominal wall affects the integrity of the respiratory muscles and thus directly affects their function. In addition, anaesthesia uses pharmacological agents such as neuromuscular blockers which affect the contraction of respiratory muscles, sometimes for a considerable time after the end of the operation. Furthermore, surgery or pharmacological agents such as sedatives which affect the neural structures of the respiratory muscles will influence their performance.

It is well known that dysfunction of the respiratory muscles due to surgery may lead to a reduction in the vital capacity (VC) and tidal volume (VT), total lung capacity (TLC) and, thus, insufficient cough. This may cause atelectasis in the basal lung segments and a decrease in functional residual capacity (FRC) which, in turn, affects the gas exchange properties of the lung by increasing the ventilation/ perfusion $(\dot{\mathrm{V}} / \dot{\mathrm{Q}})$ mismatch..$^{5-8}$ The situation may be further aggravated by hypoventilation due to several factors including sedation, pain, and increased mechanical load. As a result, hypoxia may ensue with a detrimental effect on the condition of the patient. In addition, atelectasis may be a risk factor for pulmonary infections ${ }^{9}$ which have significant morbidity and mortality in this patient population. In severe cases these consequences of respiratory muscle impairment may lead to respiratory failure and death. ${ }^{7}$

However, surgery may also improve the function of the respiratory muscles. Indeed, recent surgical procedures-particularly for severe chronic obstructive pulmonary disease - have, among other beneficial effects, a favourable influence on respiratory muscle function. ${ }^{10} 11$

In this review surgery that impairs the function of respiratory muscles is first discussed, and then surgery that is beneficial to respiratory muscle function. Practical therapeutic approaches are considered in each case. Preoperative assessment of respiratory muscle function and postoperative recommendations are also addressed.

\section{Methodological aspects}

Many of the studies that have been reviewed used volitional tests such as maximum inspiratory pressure (MIP) or maximum expiratory pressure (MEP) to investigate the effect of surgery on respiratory muscle function. These tests are easy to perform but may be affected by pain or by the personality or motivation of the patient, and sedatives such as pethidine could also influence the results. In addition, the terms "respiratory muscle impairment", "failure of respiratory muscle contractility", and "respiratory muscle dysfunction" have been used indiscriminantly and this is often confusing. However, even with these limitations and criticisms of the methodologies used, the main message - that surgery affects the function of respiratory muscles, either negatively or positively - is still valid. 


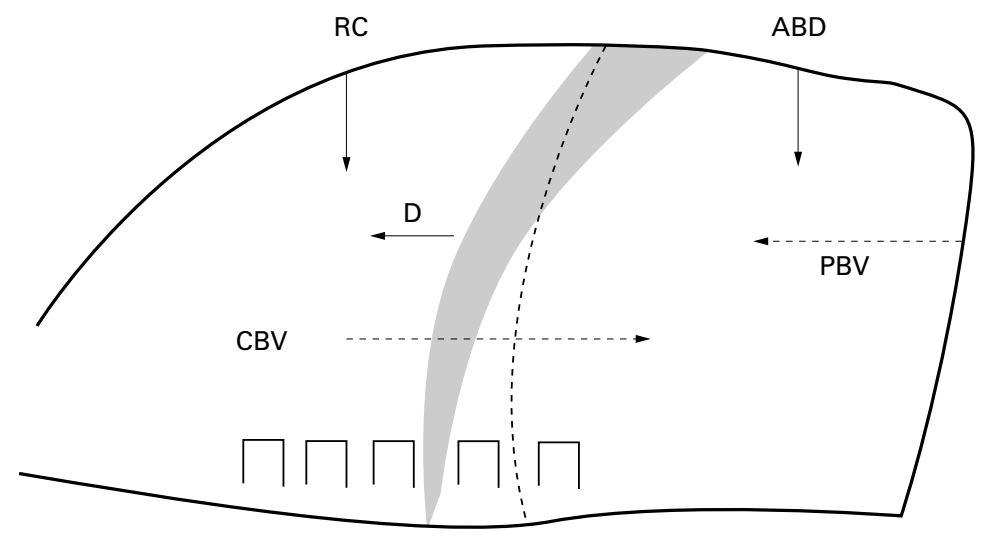

Figure 1 Rib cage (RC), abdominal (ABD) and diaphragmatic (D) volume and position changes under general anaesthesia. Dashed line represents the awake end expiratory position of the diaphragm and shaded area the diaphragmatic movements during anaesthesia (diaphragmatic shift $=-500 \mathrm{ml}$ ). The total effect is reduction in functional residual capacity (FRC $=-450 \mathrm{ml})$, central blood volume $(C B V=-300 \mathrm{ml})$, redistribution and increase in peripheral blood volume $(P B L=+100 \mathrm{ml})$. Modified from Froese and Bryan $^{5}$ and Hedenstierna et al.

\section{Surgery that impairs respiratory muscle function}

It has been shown that significant volume displacements between thoracic and abdominal cavities occur during surgery simply by changing posture (supine) and by the administration of general anaesthesia (fig 1)..$^{5-8}$ These volume changes affect the curvature of the diaphragm (Laplace's law) and move it from its resting length/tension position. As a result, its efficiency as a pressure generator changes.

The main pathophysiological mechanisms by which surgery has a detrimental effect on respiratory muscles are listed in table 1 .

\section{CARDIAC SURGERY}

Diaphragmatic impairment due to phrenic nerve dysfunction is a well recognised complication of heart surgery. ${ }^{12-18}$ It has a negative impact on the patient's overall outcome and, depending on the pulmonary reserve of the patient, prolongs ventilatory support and delays discharge from the ICU or hospital. The incidence of diaphragmatic dysfunction in patients undergoing cardiac surgery varies from $10 \%$ to $85 \%$ according to the electrophysiological, radiological or other techniques used for its detection, ${ }^{19-21}$ and is similar in adults, children and infants. ${ }^{2223}$

Although several factors have been implicated in phrenic nerve dysfunction after cardiac surgery, most of the cases are either due to cold injury or direct damage to the nerve. ${ }^{14182425}$ Other possible causes include disruption of the blood supply or stretching of the nerve. Dissection of the left internal mammary artery as a conduit for aortocoronary bypass may be associated with significant

Table 1 Pathophysiological mechanisms impairing function of respiratory muscles after surgery

Effect on neural control of respiratory muscles (e.g. phrenicotomy)

Effect on integrity of respiratory muscles by the surgical incision

Reflex mechanisms (phrenic nerve inhibition)

Change in the length/tension relationship (change in FRC)

Change in the thoracoabdominal mechanics (e.g. reduction of rib cage compliance)

Anaesthesia (pharmacological agents/loads) and postoperative pain

Specific surgical procedures (e.g. cooling during open heart surgery)

Surgery on organs affecting respiratory muscle function (e.g. parathyroidectomy) impairment in perfusion and function of the left phrenic nerve ${ }^{26}$ leading to unilateral diaphragmatic dysfunction. Direct damage to the phrenic nerve by electrocautery during the preparation of the internal mammary artery may also occur. ${ }^{26}$

Unilateral damage of the phrenic nerve is usually of little clinical significance in patients with normal pulmonary function ${ }^{27}$ but this may not be the case in patients with borderline respiratory function. On the other hand, bilateral phrenic nerve injury carries significant morbidity and necessitates, at least initially, mechanical ventilatory support. Fortunately, bilateral phrenic injury is relatively uncommon, occurring in approximately $2 \%$ of cases. ${ }^{18}$ Hypoventilation due to phrenic nerve dysfunction may be considerably exaggerated during REM sleep when the activity of other respiratory muscles is reduced..$^{28}$ However, the importance of this has not been established.

Cold induced injury to the phrenic nerve due to the use of ice slush to protect the myocardium was first reported in 1964 by Scannell. ${ }^{29}$ Since then several investigators have reached similar conclusions. ${ }^{12} 182430$ The effect of temperature on phrenic nerve and diaphragmatic function during cardiac surgery has been investigated by Mills et $a l^{24}$ who concluded that diaphragmatic function was affected even by mild hypothermia. The incidence of phrenic nerve dysfunction after topical use of ice slush has been reported to be in the range of $25-73 \% .^{18} 24293132$ Recovery of the diaphragm after cold injury may vary from 30 days to two years. ${ }^{13}$ In a recent prospective study of the risk factors for phrenic nerve dysfunction in 63 patients undergoing cardiac surgery Dimopoulou $e t a l^{18}$ reported that $21 \%$ of patients showed electrophysiologically abnormal nerve function. Among the potential risk factors the use of ice slush for myocardial preservation was the only independent factor related to phrenic nerve dysfunction with an eightfold higher incidence. ${ }^{18}$ On the other hand, the use of a cooling jacket to prevent direct contact of the phrenic nerve with the ice significantly decreased diaphragmatic dysfunction after cardiac surgery. Indeed, Bonchek et $a l^{33}$ reported no phrenic nerve injury in 750 patients in whom a cooling jacket was used. The use of cold normal saline solution has been reported to protect the myocardium adequately without adversely affecting the phrenic nerve, ${ }^{34}$ but this was not confirmed by Dimopoulou et al. ${ }^{18}$

The type of surgical incision has also been shown to affect respiratory muscle function, with sternotomy being reported to impair respiratory muscle function less than lateral thoracotomy. ${ }^{35}$ Preoperative prophylactic inspiratory muscle training has been found to reduce postoperative pulmonary complications in patients undergoing coronary artery bypass surgery. ${ }^{36}$ In addition, uncontrolled studies have indicated that the use of a rocking bed to treat diaphragmatic dysfunction after cardiac surgery may be beneficial. ${ }^{25} 37$ 
THORACIC SURGERY

Respiratory muscle function after thoracic surgery may be affected directly by damage to the muscle itself or to the nerves as a consequence of the incision, or indirectly as a result of changes in the mechanics of the respiratory system. Distortion of chest wall configuration may reduce the chest wall compliance and increase the work of breathing leading to a decrease in the mechanical efficiency of the respiratory muscles. ${ }^{38}$ The efficiency of the respiratory muscles may be further reduced by a decrease in lung compliance due to atelectasis. Theoretically, the effective respiratory muscle mass may be reduced by mechanical restriction of motion or by muscle deconditioning after major surgery, thereby further impairing the respiratory muscle response to an imposed load. This, however, needs to be investigated in more detail.

In patients with borderline respiratory muscle function the increased work of breathing, mainly due to the decrease in chest wall compliance after thoracotomy, carries considerable morbidity and mortality. ${ }^{38-41}$ It has been shown that lung resection (segmentectomy, lobectomy, pneumonectomy), particularly in patients over 70 years of age, decreases MIP and MEP. ${ }^{41}$ This decrease may last for at least four weeks after the operation. Even right sleeve resection has been reported to cause paralysis of the hemidiaphragm requiring plication. ${ }^{42}$ In addition, Maeda et al observed an increase in intercostal/accessory muscle recruitment after thoracotomy and pulmonary resection and interpreted this as indicating diaphragmatic dysfunction. ${ }^{39}$

It seems that the chest wall damage during thoracotomy may play a crucial part in the decrease in respiratory muscle strength. Indeed, a smaller decrease in MIP and MEP was observed in patients undergoing thoracoscopy and video assisted thoracic surgery (VATS). ${ }^{41}$ In an animal model diaphragmatic function was evaluated using sonomanometers after VATS or thoracotomy. The shortening fraction of the diaphragm decreases after both procedures but it recovers faster after VATS. ${ }^{43}$ Similar results were reported in humans. ${ }^{44}$ These results indicate that the changes in chest wall secondary to the incision used is one of the determinants of respiratory muscle function after thoracic surgery. Postoperative pain and the different doses of sedatives and analgesics may affect the results of volitional tests and could be an alternative explanation for the differences seen between thoracotomy and thoracoscopy. ${ }^{44-46}$ Further clarification of these findings is needed.

However, it is of interest to note that thoracic epidural anaesthesia does not prevent respiratory muscle dysfunction. Fratacci et al monitored diaphragmatic function after thoracotomy by implanting one pair of sonomicrometric crystals and two electromyographic electrodes on the costal diaphragm of six patients undergoing an elective pulmonary resection. ${ }^{46} \mathrm{~A}$ marked reduction in active diaphragmatic shortening was seen after thoracotomy which was not reversed by thoracic epidural anaesthesia, despite an improvement in other indices of respiratory function. The interpretation of these results, however, is complicated by the possibility that thoracic epidural anaesthesia may influence efferent traffic to some inspiratory and expiratory muscles. The effect of intercostal block on lung function after thoracotomy is reported to be minimal. ${ }^{45}$

Preoperative respiratory muscle training may prevent postoperative pulmonary complications by increasing both inspiratory and expiratory muscle strength in patients undergoing thoracic surgery. ${ }^{47}$ However, the effect of respiratory muscle training on sustained ventilation and maximal oxygen consumption $\left(\dot{\mathrm{V}}_{2}\right)$ is limited. ${ }^{40}$

\section{ABDOMINAL SURGERY}

It is well documented that the function of the respiratory muscles is affected during and after abdominal surgery. It has been suggested that respiratory muscle dysfunction may be responsible for a number of pulmonary complications including atelectasis and pneumonia. The side of the operation, as well as the type, are the most important factors affecting the respiratory muscles.

Indeed, it has been shown that the incidence of significant respiratory muscle dysfunction after lower abdominal surgery is very low $(2-5 \%)$ while that of upper abdominal surgery may approach $20-40 \%{ }^{48-51}$ As early as 1910 Pasteur described the influence of the site of operation on the frequency of postoperative pulmonary complications. He suggested that diaphragmatic weakness may be the cause of these complications. In 1933 it was shown by Beecher $^{5455}$ that upper abdominal surgery is associated with decreased lung volumes and adoption of a rapid shallow pattern of breathing. These findings are similar to that encountered in patients with neuromuscular diseases, suggesting that respiratory muscle dysfunction may play a significant role in this breathing pattern. This has been supported by the decrease in maximum inspiratory, transdiaphragmatic, and expiratory muscle pressures observed after upper abdominal surgery in several studies. ${ }^{48}{ }^{50} 56-58$ This decrease is sustained for 48 hours after surgery ${ }^{50}$ and may persist for a week,,$^{59}$ gradually returning to normal. Furthermore, a shift to predominantly rib cage breathing - as shown by an increase in the ratio of oesophageal to gastric pressure swings $(\Delta$ Poes/ $\Delta$ Pga $)$ or by the abdominal to rib cage excursions (fig 2)-indicates that the intercostal inspiratory muscles are more active. ${ }^{8456}$ This is because the diaphragm is the muscle that is mainly affected during upper abdominal surgery. The mechanism that underlies the reduction in diaphragmatic strength and the shift to predominantly rib cage breathing is not fully understood. Although anaesthesia and pain may be responsible for dysfunction of the respiratory muscles, studies in animals and humans support the hypothesis that an inhibitory reflex generated during the surgical procedure is the major mechanism. This reflex inhibition of the phrenic nerve output has been 
Figure 2 Plots of the anteroposterior diameter of the abdomen $\left(A B D_{A D}\right)$ versus the diameter of the rib cage $\left(R C_{A P}\right)$ in patients undergoing cholecystectomy. Each loop represents a tidal breath. $1=$ preoperative (control), $2=2-4$ hours, 3 $=6-8$ hours, $4=24$ hours, $5=48$ hours postoperative. Breathing is shifted from predominantly abdominal (1) to rib cage (2 and 3) and back again to abdominal (4 and 5) Modified from Ford et al. ${ }^{48}$

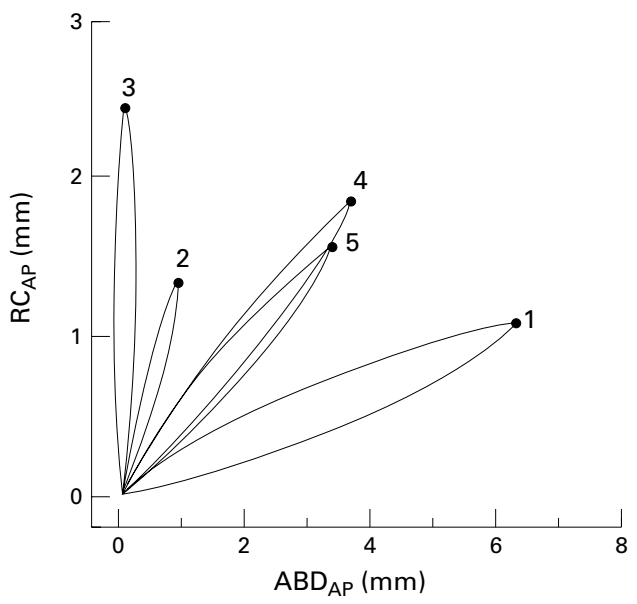

postulated to be elicited by the manipulation of the gallbladder and other splanchnic organs. ${ }^{48} 61$

Dysfunction of the respiratory muscles is greatly reduced when upper abdominal surgery is performed with laparoscopy rather than open laparotomy. ${ }^{61}$ Rovina et al assessed respiratory muscle strength after laparoscopic cholecystectomy and compared it with that after elective cholecystectomy. ${ }^{61}$ They observed that, although MIP decreased in both groups after surgery, the decrease was significantly greater in patients who had undergone open surgery, and MEP was also significantly lower in these patients. The authors postulated that the predominant mechanism for the observed difference in the global respiratory muscle strength was greater reflex inhibition of respiratory muscles in patients who underwent open surgery. However, the difference seen in MEP could be due to the intact abdominal wall during laparoscopic surgery. The lower MEP may not permit the patient undergoing open surgery to reach the same residual volume postoperatively as those undergoing laparoscopic surgery, and this may contribute to a lower value of MIP. Similar results have been reported by other investigators after laparoscopic cholecystectomy ${ }^{59-66}$ and gastroplasty via laparotomy. ${ }^{67} 68$ In addition, it has been speculated that opiates enhance this postoperative inhibitory reflex mechanism. ${ }^{49}$ Recently, a number of drugs and physical manoeuvres have been tested in order to reverse this inhibition. Jansen et $a l^{69}$ showed that doxapram, a primary stimulant of respiration (central), reduced the incidence of postoperative pulmo- nary complications and increased oxygenation after upper abdominal surgery. In addition, Siafakas $e t a l^{60}$ showed in a double blind study that aminophylline had a protective effect on respiratory muscle function against phrenic nerve inhibition after upper abdominal surgery. Finally, physical manoeuvres such as intermittent positive pressure breathing, incentive spirometry, and deep breathing exercises have been shown to prevent, to some extent, pulmonary complications after abdominal surgery. ${ }^{507071}$

Although these findings are limited to a few upper abdominal surgical procedures, it is likely that, as far as the effects of surgery on the function of respiratory muscles is concerned, similar results would be obtained in other types of upper abdominal operations including liver transplantation. For instance, McAlister et $a l^{2}$ reported a $38 \%$ incidence of right hemidiaphragm paralysis due to direct injury (crash injury) of the right phrenic nerve following orthotopic liver transplantation. This dysfunction did not have a serious effect on the outcome of the surgery. In addition, it has been reported in young children with diaphragmatic nerve paralysis due to liver transplantation that diaphragmatic plication may have a favourable impact. $^{73}$

\section{Surgery that improves respiratory muscle function}

Hyperinflation is a common feature in patients with severe chronic obstructive pulmonary disease (COPD) and has significant adverse effects on inspiratory muscle function (fig 3). Static hyperinflation affects respiratory muscles by causing them to operate at an unfavourable position on their length-tension curve and by flattening the curvature of the diaphragm. According to Laplace's law, the curvature of the diaphragm is an important determinant of its ability to produce pressure. Thus, transdiaphragmatic pressure is smaller when the diaphragm is flattened than when it is curved. In addition, hyperinflation shortens the muscle fibres of the diaphragm and probably impairs its blood supply ${ }^{74}$ while decreasing the zone of apposition and causing a medial orientation of the diaphragmatic fibres (fig 3).

It is obvious that, if hyperinflation can be reduced by surgery, the function of the respiratory muscles, in particular the diaphragm, could be improved. Two types of operations

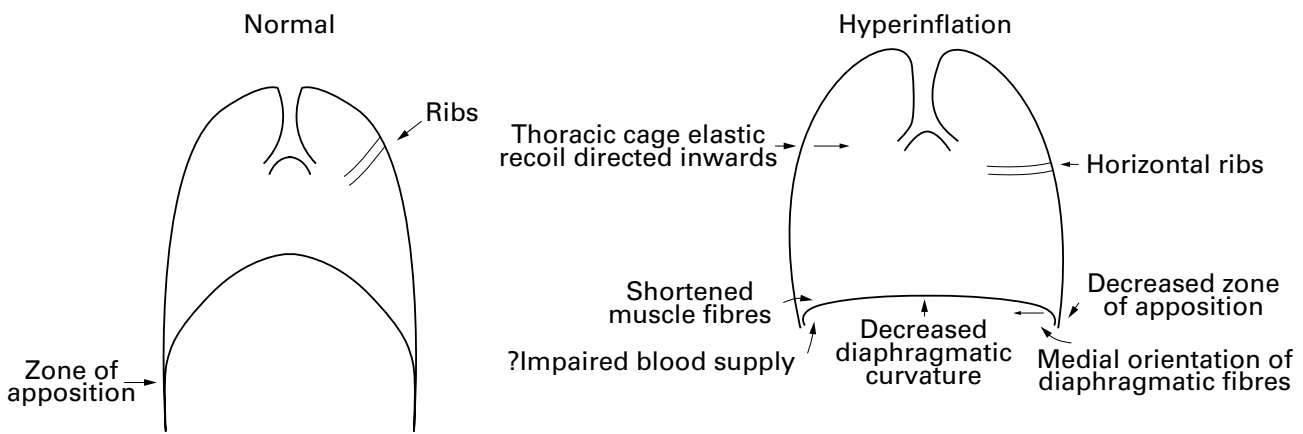

Figure 3 Summary of detrimental effects of hyperinflation on respiratory muscle function. Modified from Tobin. ${ }^{74}$ 
reduce hyperinflation-namely, lung transplantation and LVRS.

LUNG TRANSPLANTATION

In patients with COPD lung transplantation has been shown to be associated with changes in respiratory muscle function. In 1992 Williams et $a l^{75}$ reported that MIP increased significantly three months and one year after double lung transplantation. Although this finding was not discussed by the authors, it may be due to the improvement in the general condition of the patients (better motivation, improved nutrition, respiratory muscle reconditioning, improved blood gas tensions). However, subsequent studies have indicated that reduction of hyperinflation may play a pivotal role. Wanke and coworkers ${ }^{76}$ measured the sniff diaphragmatic pressure (sniff Pdi) at different volumes and analysed the relation between Pdi and lung volumes in patients with end stage COPD and in those undergoing single or double lung transplantation. In addition, they used phrenic nerve stimulation at FRC. Lung transplantation caused a reduction in lung volume and, as a consequence, sniff Pdi in these patients was higher than in the patients with COPD at all volumes analysed. However, sniff Pdi at comparable intrathoracic gas volumes was not reduced in the patients with COPD when compared with those who underwent lung transplantation. Thus, the increase in Pdi was due to the fact that the diaphragm was placed in a more favourable position for pressure generation after lung transplantation. This study indicates that changes in mechanical feedback (force-length relationship of inspiratory muscles) as a result of lung transplantation in patients with COPD may be the major determinant of the increase in diaphragmatic pressure. It also suggests that chronic static hyperinflation does not cause major functional alterations of the muscle fibres of the diaphragm. ${ }^{76}$

Although diaphragmatic strength is increased after lung transplantation in patients with severe COPD, the "neural drive" to this muscle is significantly reduced. Brath et al assessed the neural drive to the diaphragm using the diaphragmatic electromyographic activity (EMGdi) during fatiguing inspiratory threshold loading manoeuvres in patients who had undergone single or double lung transplantation. ${ }^{77}$ Compared with those who had not undergone lung transplantation, they observed a decrease in the EMG activation of the diaphragm which was also evident on the non-transplanted side in recipients of single lung transplants. Despite the reduced EMG activation, the endurance of inspiratory muscles was well preserved. The authors postulated that the reduced "neural activation" was due to the better position of the diaphragm for generating pressure. Although the diaphragmatic EMG may not always be proportional to the neural drive to the diaphragm, these results are in agreement with animal and human studies which have shown that the efferent drive to the diaphragm is well adjusted to account for changes in diaphragmatic mechanical efficiency ${ }^{78-81}$ It follows that, in addition to diaphragmatic strength, neuromechanical feedback mechanisms may also modify some aspects of the control of breathing. Finally, the decrease in central drive may contribute to the reduction in the sense of dyspnoea during ventilatory stress in activities of everyday life resulting in an improvement in the quality of life for these transplanted patients. ${ }^{11}$

It is worth pointing out that, even if the MIP and MEP are improved after heart-lung transplantation, they are still smaller than predicted values. ${ }^{82}$ This reduction cannot be solely attributed to the surgical procedure. Several preoperative and postoperative factors may be responsible for the decreased strength of the respiratory muscles. Deconditioning may play a significant role since rehabilitation programmes, including both inspiratory and expiratory muscle training, invariably increase respiratory muscle strength. ${ }^{83}{ }^{84}$ These studies, however, do not exclude learning or motivational effects on the increase in respiratory muscle strength measured by MIP and MEP.

The effect of lung or lung-heart transplantation in patients with diseases other than COPD has not been well studied. Persistent hyperinflation has been reported after heart-lung transplantation for cystic fibrosis, ${ }^{85}$ possibly due to the chest wall configuration. The change in the shape of the rib cage may represent a structural adaptation in response to chronic hyperinflation acquired during growth ${ }^{85}$ since, unlike COPD, cystic fibrosis is a disease of childhood and adolescence.

LUNG VOLUME REDUCTION SURGERY

Lung volume reduction surgery (LVRS) includes relatively new surgical techniques designed to alleviate symptoms of severe COPD mainly due to emphysema. It involves removal of part of the diseased lung tissue (usually the upper lobe) and most patients respond by a reduction in dyspnoea and improvement in exercise tolerance and quality of life..$^{106-89} \mathrm{It}$ has been shown that successful LVRS improves respiratory muscle function..$^{90-95}$ Three months after surgery the maximal transdiaphragmatic pressure (Pdimax) and twitch transdiaphragmatic response to phrenic nerve stimulation are increased. A recent study by Criner et al found a significant correlation between the increase in maximum transdiaphragmatic pressure and the reduction in FRC (trapped gas) after LVRS. ${ }^{95}$ However, other investigators have shown that these increases are greater than those that could be explained by a decrease in lung volume or by placing the diaphragm in a more favourable position on the length-tension curve. The change in mechanical feedback is therefore not the only mechanism underlying the improvement in respiratory muscle function observed after LVRS. Factors that might contribute to this disproportionate increase in Pdimax include a learning effect, a decrease in dyspnoea, an improvement in inspiratory muscle perfusion, and inspiratory muscle reconditioning. The learning effect appears to be retained for less than one week, ${ }^{96}$ making this factor an unlikely explanation for the increase 
Table 2 Medical disorders for which preoperative assessment of respiratory muscle function is needed

Patients with borderline lung function, with or without hyperinflation (COPD, asthma) Severe obesity

Deformities of thoracic cage (e.g. kyphoscoliosis)

Neuromuscular disorders

Poor nutritional states (e.g. malignancies)

Chronic glucocorticosteroid therapy

Endocrine disorders (e.g. thyroid diseases) in Pdimax. A decrease in dyspnoea due to a reduction in respiratory muscle load could cause better cooperation during the performance of the Pdimax manoeuvre by favouring greater diaphragmatic recruitment. However, the significant increase in the twitch transdiaphragmatic pressure response to phrenic nerve stimulation offers firm evidence for the effect of LVRS on diaphragmatic contractility, leaving the increase in perfusion and muscle reconditioning as possible mechanisms for the improvement seen in inspiratory muscle function. ${ }^{91}$ Indeed, if LVRS improves right ventricular function, the resulting improvement in inspiratory muscle perfusion may enhance muscle strength. ${ }^{97} 98$ This improvement may also be explained by better conditioning because of the ability of the patient to undertake more exercise due to improvements in pulmonary mechanics, skeletal muscle capacity, and cardiovascular function. ${ }^{99}$

It has been shown that the tidal breathing ratio of $\Delta \mathrm{Pga} / \Delta \mathrm{Pdi}$ increases after LVRS. ${ }^{91}{ }^{100}$ This increase could be due to an increase in the diaphragmatic contribution to tidal breathing or, when expiratory muscles contract, to a decrease in the recruitment of the expiratory muscles. ${ }^{27}$ Data from patients following LVRS support the first possibility since an early inspiratory fall in Pga, which indicates relaxation of expiratory muscles, is not a common finding in these patients. ${ }^{91} 100$ The increased contribution of the diaphragm during tidal breathing may be responsible for the reduction in recruitment of the muscles of the rib cage after surgery. Furthermore, the increased efficiency of the diaphragm as a pressure generator may cause the considerable reduction in respiratory drive observed after LVRS. It therefore seems that LVRS increases the neuromechanical coupling of the diaphragm by several mechanisms. ${ }^{91}$ This increase, combined with the de-recruitment of rib cage muscles, as suggested by the change in the $\Delta \mathrm{Pga} / \Delta \mathrm{Pdi}$ ratio, may account for the decrease in dyspnoea at rest and the increased exercise tolerance. ${ }^{91}$ Recent studies have shown that LVRS has no effect on the static mechanical properties of the chest wall ${ }^{101}$ and reinforce the improvement in pulmonary elastic recoil. ${ }^{102}$ However, further studies are needed to clarify these issues.

SURGERY FOR OBESITY

Weight lost following gastroplasty for morbid obesity is associated with improvement in lung volumes and respiratory muscle function. ${ }^{103}$

\section{Clinical applications}

PREOPERATIVE

Although respiratory muscles are impaired after most throracoabdominal surgical proce- dures, little attention is paid to preoperative assessment of their function. Spirometric tests, lung volumes (VC, FRC, RV), and measurements of MIP and MEP are simple tests for assessing respiratory muscle function. Table 2 summarises the clinical conditions in which preoperative assessment of respiratory muscle function is indicated. A normal VC without a significant fall $(<20 \%)$ when the subject lies supine virtually excludes clinically important muscle weakness. ${ }^{104} 105$ Similarly, MIP and MEP $>80 \mathrm{~cm} \mathrm{H}_{2} \mathrm{O}$ indicate adequate respiratory muscle strength and sufficient cough. ${ }^{104}$ However, we should note that MIP and MEP are volitional tests and thus require cooperation of the patients. It follows that, although high values of MIP and MEP exclude muscle weakness, the reverse is not true. Indeed, low values of MIP and MEP may be due to patient's cooperation. The easiest test designed to evaluate inspiratory muscle strength is the sniff nasal inspiratory pressure, a natural manoeuvre which many patients find easier to perform. ${ }^{105} \mathrm{~A}$ sniff nasal inspiratory pressure of $>70 \mathrm{~cm} \mathrm{H}_{2} \mathrm{O}$ indicates almost normal inspiratory muscle strength. ${ }^{104}$ The sniff test can be also performed using an oesophageal or gastric catheter to obtain either the sniff oesophageal pressure (sniff Poes) or the sniff transdiaphragmatic pressure (sniff Pdi). ${ }^{106}$ It has been shown that these tests have a better reproducibility and a narrower normal range than the sniff nasal inspiratory pressure. ${ }^{106}$ If the patient is considered to be at a high risk of developing respiratory muscle dysfunction after surgery with borderline lung function, more advanced methodology using one of the following non-volitional tests might be needed to evaluate the function of the respiratory muscles accurately: (1) electrical or magnetic stimulation of the phrenic nerve and measurement of the EMG signal, the nerve conduction time, and the twitch $\mathrm{Pdi}^{107}{ }^{108}$; (2) measurement of twitch mouth pressure after magnetic stimulation of the phrenic nerve $e^{109} 110$ which has the advantage of being non-invasive (but in patients with COPD mouth pressure does not accurately reflect inspiratory muscle pressure and this must be taken into account ${ }^{111}$ ); (3) measurement of gastric pressure during coughing to evaluate expiratory muscle strength, although normal values have yet to be formally described.

In addition, during the preoperative period respiratory physicians should discuss with the surgical team the best incision to use (sternotomy versus lateral thoracotomy), the use of less intensive surgery (laparoscopic or thoracoscopic), protection of the phrenic nerve (jacket), and should supervise respiratory muscle training. ${ }^{3647}$

\section{POSTOPERATIVE}

During the postoperative period and depending on the type of surgery performed, deep breathing exercises, incentive spirometric testing, or positive pressure breathing may be used to prevent complications. ${ }^{50} 70{ }^{71}$ In the presence of postoperative complications physicians should be aware that respiratory muscle 
dysfunction could be the cause and the function of the respiratory muscles should be assessed. Finally, aminophylline or doxapram may be given to minimise phrenic nerve inhibition when pulmonary complications occur after upper abdominal surgery. ${ }^{6069}$

\section{Conclusion}

Surgery may affect the function of respiratory muscles in a number of ways. Some types of surgical procedure adversely influence respiratory muscle function while others have a favourable effect. Changes in respiratory muscle function may be due to a direct effect of the surgical procedure on the respiratory muscles or their neural control, or to indirect mechanisms. Several complications associated with respiratory muscle dysfunction caused by surgery may increase the morbidity and mortality to a considerable extent. The physician dealing with these patients should be aware of the detrimental effects of surgery on respiratory muscles and take the appropriate measures to reduce the magnitude and complication of respiratory muscle dysfunction. On the other hand, different surgical procedures, particularly lung transplantation and lung volume reduction surgery, are unequivocally associated with improved respiratory muscle function. This improvement may be due to several factors related directly or indirectly to the respiratory muscles.

1 Mead J, Smith JC, Loring SH. Volume displacements of the chest wall and their mechanical significance. In: Roussos C, ed. The thorax. New York: Marcel Dekker, 1995: 565-86.

2 Macklem PT. The act of breathing. In: Roussos, ed. The thorax. New York: Marcel Dekker, 1995: 445-54.

3 Younes M, Remmers J. Control of tidal volume and respiratory frequency. In: Hornbein TF, ed. Lung biology in health and disease: regulation of breathing. New York: Marcel Dekker, 1981: 621-71.

4 Berger AJ. Control of breathing. In: Murray J, Nadel J, eds. Textbook of respiratory medicine. New York: WB Saunders, 1988: 49-166.

5 Froese AB, Bryan AC. Effects of anesthesia and paralysis on diaphragmatic mechanics in man. Anesthesiology 1974;41: $242-52$.

6 Hedenstierna G, Strandberg A, Brismar B, et al. Functional residual capacity, thoracoabdominal dimensions, and central blood volume during general anesthesia with muscle paralysis and mechanical ventilation. Anesthesiology 1985;62:247-54

7 Neely WA, Robinson WT, McMullan MH, et al. Postoperative respiratory insufficiency: physiological studies with therapeutic implications. Ann Surg 1970;171:679-85.

8 Nimmo AF, Drummond GB. Respiratory mechanics after abdominal surgery measured with continuous analysis of pressure, flow and volume signals. Br 7 Anaesth 1996;77: 317-26.

9 Bergman NA, Tien YK. Contribution of the closure of pulmonary units to impaired oxygenation during anesthesia. Anesthesiology 1983;59:359-401.

10 Cooper JD, Lefrak S. Is volume reduction surgery appropriate in the treatment of emphysema? Yes. Am $\mathcal{F}$ Respir Crit ate in the treatment of emphys
Care Med 1996;153:1201-4.

11 Martinez FJ, Orens JB, Whyte RI, et al. Lung mechanics and dyspnea after lung transplantation for chronic airflow dyspnea after lung transplantation for chronic airflow
obstruction. Am F Respir Crit Care Med 1996;153:1536-43.

12 Esposito RA, Spencer FC. The effect of pericardial insulation on hypothermic phrenic nerve injury during open-heart surgery. Ann Thorac Surg 1987;43:303-8.

13 Curtis JJ, Nawarawong W, Walls JT, et al. Elevated hemidiaphragm after cardiac operations: incidence, prognosis, and relationship to the use of topical ice slush. Ann Thorac Surg 1989;48:764-8.

14 Efthimiou J, Butler J, Woodham C, et al. Diaphragm paralysis following cardiac surgery: role of phrenic nerve cold injury. Ann Thorac Surg 1991;52:1005-8.

15 Wilcox P, Baile EM, Hards J, et al. Phrenic nerve function and its relationship to atelectasis after coronary artery bypass surgery. Chest 1988;93:693-8.

16 Johnson D, Hurst T, Thomson D, et al. Respiratory function after cardiac surgery. $\mathcal{F}$ Cardiothorac Vasc Anesth 1996;10: 571-7.

17 DeVita MA, Robinson LR, Rehder J, et al. Incidence and natural history of phrenic neuropathy occurring during open heart surgery. Chest 1993;103:850-6.
18 Dimopoulou I, Daganou M, Dafni U, et al. Phrenic nerve dysfunction after cardiac operations. Electrophysiologic evaluation of risk factors. Chest 1998;113:8-14.

19 Benjamin JJ, Cascade PN, Rubenfire M, et al. Left lower lobe atelectasis and consolidation following cardiac surgery: the effect of topical cooling on the phrenic nerve. Radiology 1982;142:11-14.

20 Brown KA, Hoffstein V, Byrick RJ. Bedside diagnosis of bilateral diaphragmatic paralysis in a ventilator-dependent patient after open-heart surgery. Anesth Analg 1985;64: 1208-10.

21 Clergue F, Whitelaw WA, Charles JC, et al. Inferences about respiratory muscle use after cardiac surgery from compartmental volume and pressure measurements. Anesthesiology $1995 \cdot 82: 1318-27$

22 Mok Q, Ross-Russell R, Mulvey D, et al. Phrenic nerve injury in infants and children undergoing cardiac surgery. Br Heart F 1991;65:287-92.

23 Russell RI, Helps BA, Dicks-Mireaux CM, et al. Early assessment of diaphragmatic dysfunction in children in the ITU: chest radiology and phrenic nerve stimulation. Eur Respir F 1993;6:1336-9.

24 Mills GH, Khan ZP, Moxham J, et al. Effects of temperature on phrenic nerve and diaphragmatic function during cardiac surgery. Br f Anaesth 1997;79:726-32.

25 Weiman DS, Ferdinand FD, Randolph Bolton JW, et al. Perioperative respiratory management in cardiac surgery. Clin Chest Med 1993;14:283-92.

26 O'Brien JW, Johnson SH, VanSteyn SJ, et al. Effects of internal mammary artery dissection on phrenic nerve perfusion and function. Ann Thorac Surg 1991;52:182-8.

27 Diehl JL, Lafaso F, Deleuze P, et al. Clinically relevant diaphragmatic dysfunction after cardiac operations. $\mathcal{f}$ Thorac Cardiovasc Surg 1994;107:487-98.

28 Tabachnik E, Muller NL, Bryan AC, et al. Changes in ventilation and chest wall mechanics during sleep in normal adolescents. F Appl Physiol 1981;51:557-64.

29 Scannell SG. Results of open heart operation for acquired aortic valve disease. F Thorac Cardiovasc Surg 1964;45:47-

30 Wheeler WE, Rubis LJ, Jones CW, et al. Etiology and prevention of topical cardiac hypothermia-induced phrenic nerve injury and left lower lobe atelectasis during cardiac surgery. Chest 1985;88:680-3.

31 Wilcox PG, Pare PD, Pardly RL. Recovery after unilateral phrenic injury associated with coronary artery revascularization. Chest 1990;98:661-6.

32 Takeda S, Nakahara K, Fujii Y, et al. Concomitant cardiac and pulmonary operation. Pulmonary mechanics and outcome of phrenic nerve injury. F Cardiovasc Surg 1997;38: $517-21$.

33 Bonchek LI. Myocardial protection jacket for topical hypothermia. $\mathcal{F}$ Thorac Cardiovasc Surg 1987;94:792-6.

34 Rousou JA, Parker T, Engelman RM, et al. Phrenic nerve paresis associated with the use of iced slush and the cooling jacket for topical hypothermia. F Thorac Cardiovasc Surg 1985;89:921-5

35 Peters RM, Wellons HA, Htwe TM. Total compliance and work of breathing after thoracotomy. $\mathcal{F}$ Thorac Cardiovasc Surg 1969;57:348

36 Weiner P, Zeidan F, Zamir D, et al. Prophylactic inspiratory muscle training in patients undergoing coronary artery bypass graft. World $\mathcal{F}$ Surg 1998;22:427-31.

37 Abd AG, Braun NMT, Baskin MI, et al. Diaphragmatic dysfunction after open heart surgery: treatment with a rocking bed. Ann Intern Med 1989;111:881-6.

38 Karlson KE, Seltzer B, Lee S, et al. Influence of thoracotomy on pulmonary mechanics: association of increased work of breathing during anesthesia and postoperative pulmonary complications. Ann Surg 1965;162:973-80.

39 Maeda H, Nakahara K, Ohno K, et al. Diaphragm function after pulmonary resection. Relationship to postoperative respiratory failure. Am Rev Respir Dis 1988;137:678-781.

40 Hsia CCW, Peshock RM, Estrera AS, et al. Respiratory muscle limitation in patients after pneumonectomy. Am Rev Respir Dis 1993;147:744-52.

41 Nomori H, Horio H, Fuyuno G, et al. Respiratory muscle strength after lung resection with special reference to age and procedures of thoracotomy. Eur 7 Cardiothorac Surg 1996;10:352-8.

42 Takeda S, Nakahara K, Fujii Y, et al. Plication of paralyzed hemidiaphragm after right sleeve pneumonectomy. Ann Thorac Surg 1994;58:1755-7.

43 Imanaka H, Kimball WR, Wain JC, et al. Recovery of diaphragmatic function in awake sheep after two approaches to thoracic surgery. 7 Appl Physiol 1997;83:1733-40.

44 Rovina N, Bouros D, Chalkiadakis G, et al. Respiratory muscle strength after thoracotomy and thoracoscopy. ERS Annual Congress. Eur Respir f 1995;8(suppl 19):91s.

45 Bergh NP, Dottori O, Lof BA, et al. Effect of intercostal block on lung function after thoracotomy. Acta Anaesthesiol Scand Suppl 1966;24:85-95.

46 Fratacci MD, Kimball WR, Wain JC, et al. Diaphragmatic shortening after thoracic surgery in humans. Effects of mechanical ventilation and thoracic epidural anesthesia. Anesthesiology 1993;79:654-65.

47 Nomori H, Kobayashi R, Fuyuno G, et al. Preoperative respiratory muscle training. Assessment in thoracic surgery patients with special reference to postoperative pulmonary complications. Chest 1994;105:1782-8.

48 Ford GT, Rosenal TW, Clergue F, et al. Respiratory physiology in upper abdominal surgery. Clin Chest Med 1993;14: $237-52$. 
49 Celli B. Respiratory muscle strength after upper abdominal surgery. Thorax 1993;48:683-4.

, intermittent positive pressure breathing, incentive spirometry and deep breathing exercise in preventing pulmonary complications after abdominal surgery. Am Rev Respir Dis 1984;130:12-5.

51 Jackson C. Preoperative pulmonary evaluation. Arch Intern Med 1988;148:919-22.

52 Pasteur W. Active lobar collapse of the lung after abdominal operations. Lancet 1910;ii:1080-3.

53 Pasteur W. Respiratory paralysis after diphtheria as a cause of pulmonary complications. Am f Med Sci 1890:242-7.

54 Beecher HK. The effect of laparotomy on lung volume: demonstration of a new type of pulmonary collapse. $\mathcal{F}$ Clin Invest 1933;12:651-8.

55 Beecher HK. The measured effect of laparotomy on the respiration. F Clin Invest 1933;12:639-50.

piration. F Clin Invest 1933;12:639-50.
56 Ford GT, Whitelaw WA, Rosinal WT, et al. Diaphragm function after abdominal surgery in humans. Am Rev Respir Dis 1983;127:431-6.

57 Simonneau G, Vivien V, Sartene R, et al. Diaphragmatic dysfunction induced by upper abdominal surgery: role of

postoperative pain. Am Rev Respir Dis 1983;128:899-903.
Watters JM, Clancey SM, Moulton SB, et al. Impaired recovery of strength in older patients after major abdominal surgery. Ann Surg 1993;218:380-90.

59 Putensen-Himmer G, Putensen C, Lammer H, et al. Comparison of postoperative respiratory function after laparoscopy or open laparotomy for cholecystectomy. Anesthesiology 1992;77:675-80.

60 Siafakas NM, Stoubou A, Stathopoulou M, et al. Effect of aminophylline on respiratory muscle strength after upper abdominal surgery: a double blind study. Thorax 1993;48: 693-7.

61 Rovina N, Bouros D, Tzanakis N, et al. Effects of laparoscopic cholesystectomy on global respiratory muscle strength. Am f Respir Crit Care Med 1996;153:458-61.

62 Volpino P, Cangemi V, D'Andrea N, et al. Hemodynamic and pulmonary changes during and after laparoscopic
cholecystectomy. A comparison with traditional surgery. Cholecystectomy. A comparis

63 Erice F, Fox GS, Salib YM, et al. Diaphragmatic function before and after laparoscopic cholesystectomy. Anesthesiology 1993;79:966-75.

64 Couture JG, Chartrand D, Gagner M, et al. Diaphragmatic and abdominal muscle activity after endoscopic cholesystectomy. Anesth Analg 1994;78:733-9.

65 Chuter TA, Weissman C, Mathews DM, et al. Diaphragmatic breathing maneuvers and movement of the diaphragm after cholecystectomy. Chest 1990;97:1110-4.

66 Drummond GB. Diaphragmatic dysfunction: an outmoded concept. Br f Anaesth 1998;80:277-9.

67 Joris JL, Hinque VL, Laurent PE, et al. Pulmonary function and pain after gastroplasty performed via laparotomy or laparoscopy in morbidly obese patients. Br f Anaesth 1998; 80:283-8.

68 Weiner P, Waizman J, Weiner M, et al. Influence of excessive weight loss after gastroplasty for morbid obesity on respiraweight loss after gastroplasty for morbid obesity on

69 Jansen JE, Sorensen AI, Naesh O, et al. Effects of doxapram on postoperative pulmonary complications after upper abdominal surgery in high-risk patients. Lancet 1990;335 936-8

70 Chuter TA, Weissman C, Starker PM, et al. Effect of incentive spirometry on diaphragmatic function after surgery. Surgery 1989;105:488-93.

71 Celli B. Perioperative respiratory care of the patient undergoing upper abdominal surgery. Clin Chest Med 1993;14: 253-61.

72 McAlister VC, Grant DR, Roy A, et al. Right phrenic nerve injury in orthotopic liver transplantation. Tranplantation 1993;55:826-30.

73 Smyrniotis V, Andreani P, Muiesan P, et al. Diaphragmatic nerve palsy in young children following liver transplantation. Successful treatment by plication of the diaphragm. tion. Successful treatment by
Transplant Int 1998;11:281-3.

74 Tobin MJ. Respiratory muscles in disease. Clin Chest Med 1988;9:263-6.

75 Williams TJ, Patterson GA, McClean PA, et al. Maximal exercise testing in single and double lung transplant recipients. Am Rev Respir Dis 1992:145:101-5.

76 Wanke T, Merkle M, Formanek D, et al. Effect of lung transplantation on diaphragmatic function in patients with chronic obstructive pulmonary disease. Thorax 1994;49: 459-64.

77 Brath H, Lahrmann H, Wanke T, et al. The effect of lung transplantation on the neural drive to the diaphragm in patients with severe COPD. Eur Respir f 1997;10:424-9.

78 Banzett RB, Inbar GF, Brown R, et al. Diaphragm electrical activity during negative lower torso pressure in quadriplegic man. I Appl Physiol: Respirat Environ Exercise Phiysiol 1981;51:654-9.

79 Cheeseman M, Revelette WR. Phrenic afferent contribution to reflexes elicited by changes in diaphragm length. $\mathcal{F} A p p l$ Physiol 1990;69:640-7.

80 Green M, Mead J, Sears TA. Muscle activity during chest wall restriction and positive pressure breathing in man. wall restriction and positive pr
Respir Physiol 1978;35:283-300.

81 Reid MB, Banzett RB, Feldman HA, et al. Reflex compensation of spontaneous breathing when immersion changes diaphragm length. F Appl Physiol 1985;58:113642 .
82 Dorffner R, Eibenberger K, Youssefzadeh S, et al. Diaphragmatic dysfunction after heart or lung transplantation. $\mathcal{F}$ Heart Lung Transplant 1997;16:566-9.

83 Kesten S. Pulmonary rehabilitation and surgery for end-stage lung disease. Clin Chest Med 1997;18:173-81.

84 Ambrosino N, Bruschi C, Callegari G, et al. Time course of exercise capacity, skeletal and respiratory muscle performance after heart-lung transplantation. Eur Respir f 1996;9: $1508-14$.

85 Guignon I, Cassart M, Gevenois PA, et al. Persistent hyperinflation after heart-lung transplantation for cystic fibrosis. Am J Respir Crit Care Med 1995;151:534-40.

86 Cooper JD, Trulock RP, Triantafillou AN, et al. Bilateral pneumectomy (volume reduction) for chronic obstructive pulmonary disease. I Thorac Cardiovasc Surg 1995;109: 106-19.

87 Fein AM, Branman SS, Casaburi R, et al. Lung volume reduction surgery. Am f Respir Crit Care Med 1996;154: 1151-2.

88 Ferguson GT, Fernandez E, Zamora MR, et al. Improved exercise performance following lung volume reduction surgery for emphysema. Am $\mathcal{F}$ Respir Crit Care Med 1998;157: gery for em

89 Russi EW, Stammberger U, Weder W. Lung volume reduction surgery for emphysema. Eur Respir f 1997;10:208-18.

90 Martinez FJ, de Oca MM, Whyte RI, et al. Lung-volume reduction improves dyspnea, dynamic hyperinflation and respiratory muscle function. Am $\mathcal{f}$ Respir Crit Care Med 1997; 155:1984-90.

91 Laghi F, Jubran A, Topeli A, et al. Effect of lung volume reduction surgery on neuromechanical coupling of the diaphragm. Am $\mathcal{7}$ Respir Crit Care Med 1998;157:475-83.

92 Teschler H, Stamatis G, el-Raouf Farhat AA, et al. Effect of surgical lung volume reduction on respiratory muscle function in pulmonary emphysema. Eur Respir f 1996;9:177984

93 Tschernko EM, Wisser W, Wanke T, et al. Changes in ventilatory mechanics and diaphragmatic function after lung volume reduction surgery in patients with COPD. Thorax 1997;52:545-50.

94 Travaline JM, Addonizio VP, Criner GJ. Effect of bullectomy on diaphragm strength. Am $\mathcal{F}$ Respir Crit Care Med 1995;152:1697-701.

95 Criner G, Cordova FC, Leyenson V, et al. Effect of lung volume reduction surgery on diaphragm strength. Am 7 Respir Crit Care Med 1998;157:1578-85.

96 Wen AS, Woo MS, Keens TG. How many maneuvers are required to measure maximal inspiratory pressure accurately? Chest 1997;111:802-7.

97 Sciurba FC, Rogers RM, Keenan RJ, et al. Improvement in pulmonary function and elastic recoil after lung reduction surgery for diffuse emphysema. N Engl f Med 1996;334: 1095-6.

98 McParland C, Resh EF, Krishnan, et al. Inspiratory muscle weakness in chronic heart failure: role of nutrition and electrolyte status and systemic myopathy. Am $\mathcal{f}$ Respir Crit Care Med 1995;151:1101-7.

99 Maltais F, LeBlanc P, Simard C, et al. Skeletal muscle adaptation to endurance training in patients with chronic obstructive pulmonary disease. Am $\mathcal{F}$ Respir Crit Care Med 1996;154:442-7.

100 Benditt JO, Wood DE, McCool FD, et al. Changes in breathing and ventilatory muscle recruitment patterns induced by lung volume reduction surgery. Am F Respir Crit Care Med 1997;155:279-84.

101 Jubran A, Laghi F, Mazur M, et al Partitioning of lung and chest-wall mechanics before and after lung-volumereduction surgery. Am $\mathcal{f}$ Respir Crit Care Med 1998;158: 306-10.

102 Norman M, Hillerdal G, Orre L, et al. Improved lung function and quality of life following increased elastic recoil after lung volume reduction surgery in emphysema. Respir Med 1998;92:653-8.

103 Weiner P, Waizman J, Weiner M, et al. Influence of excessive weight loss after gastroplasty for morbid obesity on respiratory muscle performance. Thorax 1998;53:39-42.

104 Polkey MI, Green M, Moxham J. Measurement of respiratory muscle strength. Thorax 1995;50:1131-5.

105 Macklem PT. Muscular weakness and respiratory function. N Engl f Med 1986;314:775-6.

106 Miller JM, Moxham J, Green M. The maximal shift in the assessment of diaphragm function in man. Clin Sci 1985;69:91-6.

107 Chen R, Collins S, Remtulla H, et al. Phrenic nerve conduction study in normal subjects. Muscle Nerve 1995;18:330-5.

08 Similowski T, Fleury B, Launois S, et al. Cervical magnetic stimulation: a new painless method for bilateral phrenic nerve stimulation in conscious humans. F Appl Physiol $1989 ; 67: 1311-8$

109 Yan S, Gauthier AP, Similowski T, et al. Evaluation of human diaphragm contractility using mouth pressure twitches. Am Rev Respir Dis 1992;145:1064-9.

110 Hamnegard C-H, Wragg S, Kyroussis D, et al. Mouth pressure in response to magnetic stimulation of the phrenic nerves. Thorax 1995;50:620-4.

111 Similowski T, Gauthier AP, Yan S, et al. Assessment of diaphragm function using mouth pressure twitches in chronic obstructive pulmonary disease patients. Am Rev Respir Dis 1993;147:850-6. 